\title{
Investigation of Electrogenic Partial Reactions in Detergent-Solubilized Na,K-ATPase ${ }^{\dagger}$
}

\author{
Michael Habeck, ${ }^{\ddagger}$ Erica Cirri, ${ }^{\star}$ Adriana Katz, ${ }^{\S}$ Steven J. Karlish, ${ }^{\S}$ and Hans-Jürgen Apell ${ }^{*}$, \\ ${ }^{*}$ Department of Biology, University of Konstanz, 78464 Konstanz, Germany, and ${ }^{\S}$ Department of Biological Chemistry, \\ Weizmann Institute of Science, Rehovot 76100, Israel
}

\begin{abstract}
A method for investigating electrogenic partial reactions in the pump cycle of membrane-bound P-type ATPases with electrochromic fluorescent dyes has been extended to detergent-solubilized native and purified recombinant $\mathrm{Na}, \mathrm{K}-\mathrm{ATPase}$. As a first step, it has been shown here that the function and ion binding properties of the detergent-soluble and membrane-bound rabbit renal $\mathrm{Na}, \mathrm{K}$-ATPase are not significantly different. Thus, the new assay overcomes a previous limitation of the styryl dye method, in that the protein need not be embedded in a membrane at a high density. As an example of an application of this method, transport properties of recombinant Na,K-ATPase purified from yeast cells have been studied. We have investigated and compared $\mathrm{Na}^{+}$and $\mathrm{K}^{+}$binding properties of purified detergent-soluble human $\alpha 1 /$ his- $\beta 1$ and $\alpha 2 /$ his- $\beta 1$ isoforms of the sodium pump. The only significant difference found with respect to ion binding between both isoforms is an almost 3-fold lower affinity for $\mathrm{K}^{+}$binding in the E2P state of the $\alpha 2 /$ his- $\beta 1$ isoform. This technique should be readily applicable to various other P-type ATPases or transport proteins such as carriers or ion channels that can be purified in a detergent-soluble active form.
\end{abstract}

Active ion transport across cell membranes is a key mechanism of life. The proteins responsible for this process are called ion pumps, among which the P-type ATPases are an important family of ion transporters $(1-4)$. Numerous studies of structurefunction relations of these enzymes have been undertaken, and probably the best investigated of the cation pumps are the ubiquitous $\mathrm{Na}, \mathrm{K}$-ATPase, ${ }^{1}$ the Ca-ATPase of the sarcoplasmic reticulum (SERCA), and the gastric H,K-ATPase.

In recent years, the SERCA has been successfully crystallized in different conformations and the corresponding structures have been analyzed with resolutions between 2 and $4 \AA(5-8)$. The first highly resolved structures of the $\mathrm{Na}, \mathrm{K}$-ATPase have become available recently $(9,10)$, and also a structure of the $\mathrm{Na}, \mathrm{K}$ ATPase with bound ouabain (11). The high degree of homology in the amino acid sequence and secondary structure of all three P-type ATPases suggest that homology modeling may be a useful tool for improving our understanding of structural details in conformations of the Na,K-ATPase, which have not yet been crystallized (12). The directly demonstrated similarity between $\mathrm{Na}, \mathrm{K}-\mathrm{ATP}$ ase and SERCA structures with respect to the catalytic $\alpha$ subunit adds confidence to all the conclusions drawn so far from homology modeling of the Na,K-ATPase $(9,10)$.

Functional properties have been and are being investigated extensively by various biochemical and biophysical approaches. The basic pump mechanism, the so-called Post-Albers cycle (Figure 2A) $(13,14)$, is now well established for all three P-type ATPases mentioned above (15) and is assumed as a general

\footnotetext{
This work was financially supported by the German Israeli Founda tion, GIF Research Grant 922 165.9/2006.

*To whom correspondence should be addressed. Phone: + 497531 882253. Fax: +497531 883183. E mail: h j.apell@uni konstanz.de.

${ }^{1}$ Abbreviations: Na,K ATPase, sodium and potassium ion activated adenosine triphosphatase; RH421, $N$ (4 sulfobutyl) $4\{4$ [ $p$ (dipentylamino) phenyl]butadienyl $\}$ pyridinium inner salt; DDM, $n$ dodecyl $\beta$ D malto side; $\mathrm{C}_{12} \mathrm{E}_{8}$, octaethylene glycol monododecyl ether; DOPS, 1,2 dio leoyl $s n$ glycero 3 (phospho L serine); SOPS, 1 stearoyl 2 oleoyl $s n$ glycero 3 (phospho L serine).
}

principle for all P-type ATPases. The question of how the ions are translocated from one side of the membrane to the other, at which step of the Post-Albers cycle the ions are moved and how far, has turned out to provide important information about the molecular transport process and allow the formulation of significant constraints for theoretical models of the mechanism (1). Apart from electrophysiological techniques which can be applied in the case of the Na,K-ATPase (16-19), an optical technique that exploits the electrochromic behavior of fluorescent styryl dyes in monitoring charge (ion) movements in the membrane domain of the three P-type ATPases mentioned above has been developed and used extensively $(20-23)$. In contrast to the electrophysiological methods, this technique can be used with isolated membrane preparations in the form of small or electrically leaky vesicles or open membrane patches with diameters in the micrometer range. The common feature of both these approaches is the exploitation of the electrogenicity, which is caused by the fact that the Na,K-ATPase moves ions through the apolar membrane dielectric and thus acts as an electric current generator when it runs through its pump cycle (24).

The styryl dyes applied in these measurements have an extremely high partition coefficient in favor of the hydrophobic core of the lipid phase of the membrane [250000 (20)] and show a blue or red shift of the excitation spectrum with positive or negative changes in the local electric field in the membrane, respectively $(20,21)$. These changes of the electric field are induced by the cation pumps when cations move in and out of the membrane domain. Since the detection mechanism is based on the movement of a delocalized positive charge from the pyridinium to the aniline moiety of the dye (25), the time resolution is significantly higher than that of charge movements in the cation pumps themselves.

To obtain significant fluorescence changes upon binding or release of cations to the ATPases, a precondition is that the dye molecules are close to the transmembrane domain of the cation pumps. In other words, the pump density in the membrane 


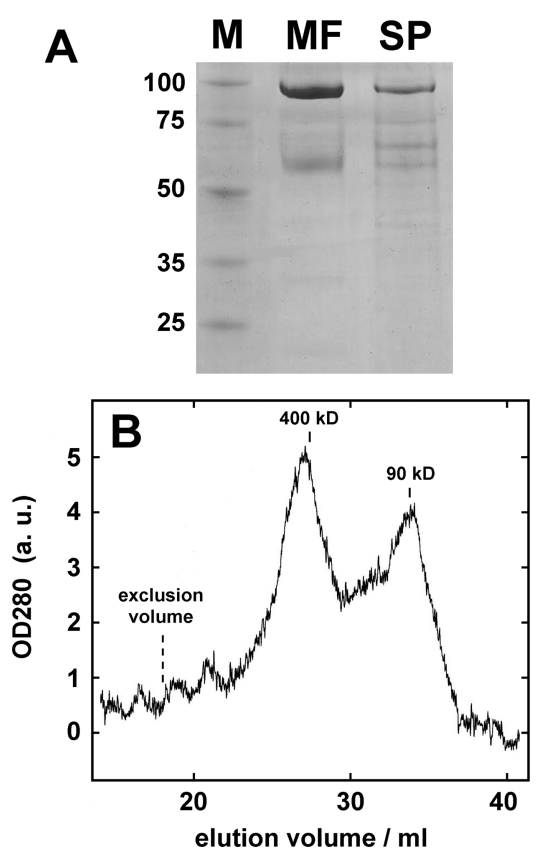

FIgure 1: Analysis of DDM solubilized Na,K ATPase. (A) SDS PAGE of Na,K ATPase from isolated membrane fragments (MF) and detergent solubilized protein (SP) compared with marker enzymes (M). While the membrane fragments show significant bands only for the $\alpha$ and $\beta$ subunits, in the detergent solubilized enzyme minor additional bands are visible with molar masses of $\sim 60$ and $\sim 75 \mathrm{kDa}$. Ten micrograms of protein was loaded per lane. (B) Size exclusion HPLC of $250 \mu \mathrm{g}$ of solubilized $\mathrm{Na}, \mathrm{K}$ ATPase from rabbit kidney. The HPLC profile shows two prominent peaks which are assigned to the solubilized enzyme micelles (at $\sim 400 \mathrm{kDa}$ ) and to lipid and detergent micelles (at $\sim 90 \mathrm{kDa}$ ).

preparations must be high (21). This represents a serious limitation, since only pumps that can be isolated in membrane preparations with intrinsically high densities of the ATPases can be studied by this method.

As reported recently, genetically engineered $\mathrm{Na}, \mathrm{K}$-ATPase (porcine and human $\alpha 1 \beta 1$ ) has been expressed in yeast such as Pichia pastoris (26) and purified. Stable detergent-soluble enzyme preparations can now be obtained in milligram quantities $(27$, 28). In particular, purification and stabilization of human $\alpha 2 \beta 1$ isoform complexes have also been described (29). These preparations consisting of soluble mixed complexes containing $\mathrm{Na}, \mathrm{K}$ ATPase, lipids, and detergent can now be utilized for further detailed biochemical and biophysical investigations. To extend the application of styryl dyes successfully from membraneembedded proteins to such solubilized recombinant Na,K-ATPase preparations, we performed the following study. In a first step, purified rabbit renal Na,K-ATPase was solubilized with DDM, electrogenic partial reactions were studied, and the results were compared with those of the well-characterized membranebound renal Na,K-ATPase. In a second step, it has been shown that the technique can be applied to recombinant human $\mathrm{Na}, \mathrm{K}-\mathrm{ATPase}$ isoforms purified from $P$. pastoris cells.

\section{MATERIALS AND METHODS}

Materials. Phosphoenolpyruvate (PEP), pyruvate kinase (PK), lactate dehydrogenase (LDH), nicotinamide adenine dinucleotide (NADH), bovine serum albumin (BSA), and ATP (disodium salt, special quality) were obtained from Boehringer. $n$-Dodecyl $\beta$-D-maltoside (DDM) was obtained from Calbiochem or Anatrace. The electrochromic styryl dye RH421 was
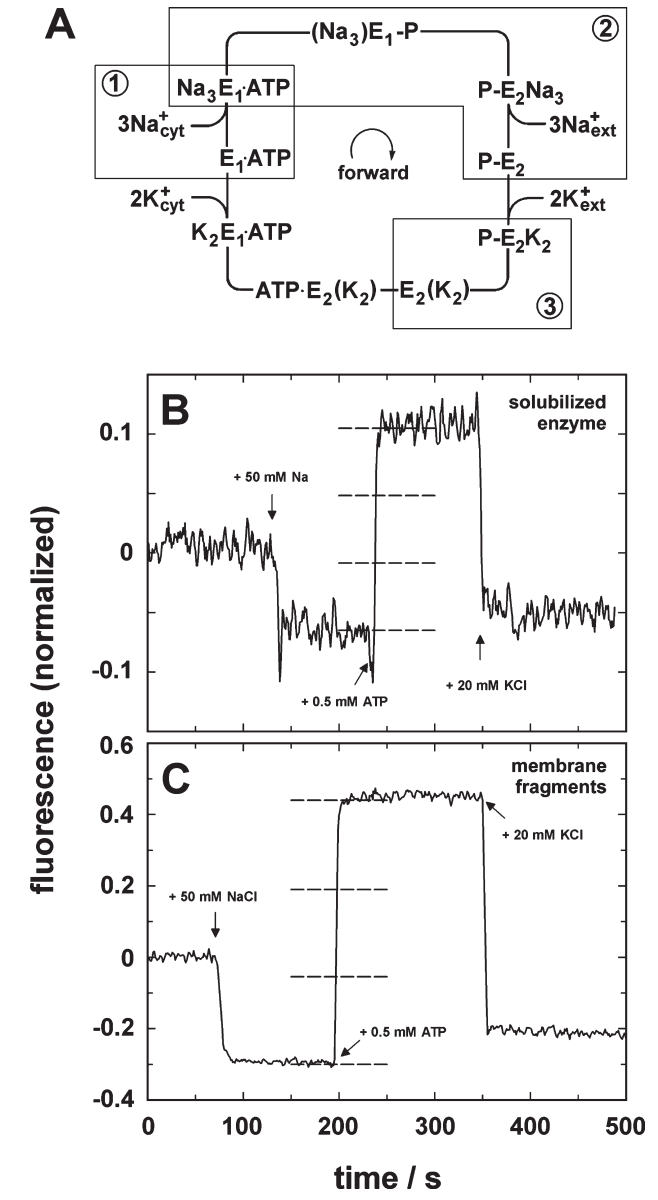

FIgure 2: Post Albers cycle of the Na,K ATPase under physiolo gical conditions (A) and standard experiments with the styryl dye RH421 performed with DDM solubilized Na,K ATPase (B) and with membrane fragments (C). (A) In the $\mathrm{E}_{1}$ conformation, the ion binding sites are accessible to the cytoplasm and allow exchange of two potassium ions against three sodium ions. In the $\mathrm{E}_{2}$ conforma tion, the reverse exchange is performed with the extracellular med ium. In the "occluded" states, $\left(\mathrm{Na}_{3}\right) \mathrm{E}_{1} \mathrm{P}, \mathrm{E}_{2}\left(\mathrm{~K}_{2}\right)$, and ATP. $\mathrm{E}_{2}\left(\mathrm{~K}_{2}\right)$, the bound ions are trapped inside the membrane domain, unable to exchange with the aqueous phases. Three boxes depict specific partial reactions: (1) cytoplasmic $\mathrm{Na}^{+}$binding (in the absence of ATP, it corresponds to the first step of the standard experiments); (2) $\mathrm{Na}^{+}$ transport and release, which occur upon addition of ATP, the second step in the standard experiments; and (3) enzyme dephosphorylation (performed in the reverse direction in the case of the backdoor phosphorylation). (B and C) In both standard experiments, $9 \mu \mathrm{g}$ of $\mathrm{Na}, \mathrm{K}$ ATPase was equilibrated in a medium containing $200 \mathrm{nM}$ RH421, $25 \mathrm{mM}$ imidazole, $0.5 \mathrm{mM}$ EDTA, and $5 \mathrm{mM} \mathrm{MgCl}_{2}$ ( $\mathrm{pH}$ 7.2). The arrows point to the addition of the specified amounts of substrates. The dashed lines indicate the fluorescence levels according to the number of ions bound to the protein: lowest level, $\mathrm{Na}_{3} \mathrm{E}_{1}$ state (three ions bound); uppermost level, $\mathrm{E}_{2} \mathrm{P}$ state (no ion in the binding sites).

received from MoBiTec, and 1,2-dioleoyl-sn-glycero-3-(phospho-L-serine) (DOPS) and 1-stearoyl-2-oleoyl-sn-glycero-3-(phospho-L-serine) (SOPS) were from Avanti Polar Lipids. Octaethylene glycol monododecyl ether $\left(\mathrm{C}_{12} \mathrm{E}_{8}\right)$ was obtained from Bachem, and BD-Talon metal affinity resin (catalog no. 635503) was from Clontech. All other reagents were purchased from Merck or Sigma-Aldrich at the highest quality available.

Enzyme Preparation from Rabbit Kidneys. Microsomal fractions containing $\mathrm{Na}, \mathrm{K}-\mathrm{ATPase}$ were prepared from the outer medulla of rabbit kidney according to procedure $\mathrm{C}$ of Jørgensen (30). Subsequently, the microsomes were incubated in a solution of $4 \mathrm{M}$ urea for $20 \mathrm{~min}$ on ice and concentrated by 
centrifugation. The pellet was resuspended in a small volume of the urea solution and solubilized with DDM in $2 \mathrm{mM}$ Tricine/ Tris ( $\mathrm{pH} 7.2$ ), $2.5 \%$ glycerol, and $50 \mu \mathrm{M}$ ATP. The ratio between microsomes and DDM was varied to yield the maximum ATPase activity of the solubilized enzyme. The best results were obtained at a microsome:DDM ratio of 2:1 (w/w). ATP was added to stabilize the protein during the incubation in the DDM solution. Unsolubilized material was removed by centrifugation (Beckman Airfuge, $160000 \mathrm{~g}$ for $15 \mathrm{~min}$ ). The solubilized protein was stored on ice without significant loss of activity for 7-8 days until it was used in experiments. The specific ATPase activity was measured by the pyruvate kinase/lactate dehydrogenase assay (3I), and the protein concentration was determined by the Lowry method using BSA as a standard. In the unpurified microsomal fraction, the specific activity was $\sim 150 \mu \mathrm{mol}$ of $\mathrm{P}_{\mathrm{i}} \mathrm{mg}{ }^{1} \mathrm{~h}{ }^{1}$ at $37^{\circ} \mathrm{C}$ with $50 \%$ ouabain-inhibited activity. The enzyme activity of the solubilized microsomes was in the range of $160-180 \mu \mathrm{mol}$ of $\mathrm{P}_{\mathrm{i}} \mathrm{h}^{1}$ (mg of protein) ${ }^{1}$, and $94 \pm 2 \%$ of the activity could be inhibited by ouabain. The lower enzyme activity of the soluble microsomal preparation compared to that of the purified $\mathrm{Na}, \mathrm{K}$ ATPase [ca. $1500 \mu \mathrm{mol}$ of $\mathrm{P}_{\mathrm{i}} \mathrm{h}^{1}$ (mg of protein) ${ }^{1}$ ] is due to the fact that it is not purified and perhaps also to a nonoptimized lipid composition of protein/lipid/detergent micelles.

The quality of the solubilized Na,K-ATPase was checked by SDS gel electrophoresis. A typical result from one preparation is shown in Figure 1A. In the gel electrophoresis, the protein composition of a purified membrane preparation (MF) is compared with that of a DDM-solubilized microsomal protein (SP). The $\alpha$ and $\beta$ subunits with molar masses of $\sim 95$ and $\sim 55 \mathrm{kDa}$, respectively, are clearly visible in both preparations. In the case of the solubilized enzyme, minor impurities with molar masses of $\sim 60$ and $\sim 75 \mathrm{kDa}$ were observed. For the purpose of establishing the styryl dye technique for the study of electrogenic partial reactions in the detergent-solubilized $\mathrm{Na}, \mathrm{K}$-ATPase, we thought it sufficient to use this soluble microsomal preparation. As a control, comparable solubilization experiments were also performed with the purified membrane-bound renal $\mathrm{Na}, \mathrm{K}$ ATPase. The resulting RH421 fluorescence signals did not differ significantly in the two preparations.

The size of the complexes consisting of Na,K-ATPase, lipids, and detergent molecules was determined by size-exclusion HPLC as described in ref 27. With a Superdex 200 column (GE Healthcare) and a running buffer of $150 \mathrm{mM} \mathrm{NaCl}, 50 \mathrm{mM}$ Hepes ( $\mathrm{pH} 7.2$ ), and $0.2 \mathrm{mg} / \mathrm{mL} \mathrm{DDM}$, the micelles were separated (Figure 1B). Calibration of the column was performed with the reference proteins conalbumin $(75 \mathrm{kDa})$ and ferritin (440 kDa) (data not shown). Two peaks with molar masses of approximately 400 and $90 \mathrm{kDa}$ could be identified. In agreement with published data, the peaks were assigned to mixed protein/ lipid/detergent micelles (at ca. $400 \mathrm{kDa}$ ) and lipid/detergent micelles (27).

Enzyme Preparation from P. pastoris. The human $\alpha 1 /$ his$\beta 1$ and $\alpha 2 /$ his- $\beta 1$ isoforms of $\mathrm{Na}, \mathrm{K}-\mathrm{ATPase}$ were expressed in $P$. pastoris as described recently (27). The cells were broken with glass beads, and urea-treated membranes were prepared (27). Approximately $1 \mathrm{~g}$ of membrane protein was obtained per $100 \mathrm{~g}$ of cells. The human $\alpha 1 /$ his $10-\beta 1$ and $\alpha 2 /$ his $10-\beta 1$ complexes were purified from the $P$. pastoris membranes by metal chelate chromatography (BD-Talon) as described in refs (27-29). Briefly, the membranes were solubilized with DDM, and the $\alpha 1 /$ his- $\beta 1$ and $\alpha 2 /$ his- $\beta 1$ complexes were purified by BD-Talon $\left(\mathrm{Co}^{2+}\right.$ beads) affinity chromatography $(27,29)$. The proteins were eluted from the beads in a solution containing $180 \mathrm{mM}$ imidazole, $20 \mathrm{mM}$ Tricine ( $\mathrm{pH}$ 7.4), $100 \mathrm{mM} \mathrm{NaCl}, 0.1 \mathrm{mg} / \mathrm{mL}$ $\mathrm{C}_{12} \mathrm{E}_{8}, 0.05 \mathrm{mg} / \mathrm{mL}$ SOPS, $0.01 \mathrm{mg} / \mathrm{mL}$ cholesterol, and $10 \%$ glycerol. Approximately $100 \mu \mathrm{g}$ of purified enzyme was obtained from $100 \mathrm{mg}$ of membranes.

Steady-State Fluorescence Measurements. Fluorescence measurements were taken in a Perkin-Elmer LS 50B fluorescence spectrophotometer as described recently (32). The excitation wavelength was set to $580 \mathrm{~nm}$ and the emission wavelength to $660 \mathrm{~nm}$ (slit widths of 15 and $20 \mathrm{~nm}$, respectively). Equilibrium titration experiments were performed in standard buffer containing $25 \mathrm{mM}$ histidine and $0.5 \mathrm{mM}$ EDTA (pH 7.2). Subsequently, $200 \mathrm{nM}$ RH421 and $9-10 \mu \mathrm{g} / \mathrm{mL}$ membrane fragments containing Na,K-ATPase or detergent-solubilized Na,K-ATPase were added to the thermostated cuvette and equilibrated until a stable fluorescence signal, $F_{0}$, was obtained. Titrations were conducted via addition of small aliquots of the indicated salt solutions from various concentrated stocks until no further changes in fluorescence could be observed. To allow a comparison between different titration experiments, normalized fluorescence changes with respect to $F_{0}\left[\Delta F / F_{0}=\left(F-F_{0}\right) / F_{0}\right]$ were calculated. Specific fluorescence levels could be assigned to defined states in the pump cycle of the Na,K-ATPase (33). All experiments were performed at $20 \pm 0.5^{\circ} \mathrm{C}$.

\section{RESULTS}

RH421 Standard Experiments. Apart from the normal quality control of Na,K-ATPase preparations, assessed by measuring the ouabain-inhibited enzyme activity, the so-called standard RH421 experiment can be used to characterize the function of the isolated ion pumps (Figure 2). As described in Materials and Methods, the $\mathrm{Na}, \mathrm{K}$-ATPase preparation is equilibrated in the fluorescence spectrophotometer in a cuvette containing the standard buffer without $\mathrm{Na}^{+}$or $\mathrm{K}^{+}$ions but containing $5 \mathrm{mM} \mathrm{MgCl}_{2}$. Under this condition, the $\mathrm{Na}$, K-ATPase is trapped in a state, $\mathrm{H}_{n} \mathrm{E}_{1}$, in which the binding sites are occupied by protons, where $n \approx 1.8$ on average at $\mathrm{pH} 7.2$, and in a $\mathrm{pH}$ dependent manner (34). After addition of $\mathrm{NaCl}$ to a final concentration of $50 \mathrm{mM}$, which is a saturating $\mathrm{Na}^{+}$concentration, the ion pumps undergo a complete transition to the $\mathrm{Na}_{3} \mathrm{E}_{1}$ state. Subsequent addition of $500 \mu \mathrm{M}$ ATP causes the protein to be phosphorylated to $\left(\mathrm{Na}_{3}\right) \mathrm{E}_{1}-\mathrm{P}$ and then undergo the conformational change transition to $\mathrm{E}_{2}-\mathrm{P}$ from which all three $\mathrm{Na}^{+}$ions are released due to the greatly decreased binding affinity for $\mathrm{Na}^{+}$. When, subsequently, $20 \mathrm{mM} \mathrm{KCl}$ is added, all substrates for the $\mathrm{Na}, \mathrm{K}$-ATPase are present to maintain the enzyme under turnover conditions, and the pumps will accumulate, on average, in the state(s) preceding the rate-limiting step(s) of the pump cycle. The different occupation of the ion binding sites is reflected in the response to addition of $\mathrm{Na}$ ions, then $\mathrm{ATP}$, and $\mathrm{K}$ ions (Figure 2B,C). It has been shown that the fluorescence response of the electrochromic styryl dye is linearly dependent on the electric field and, as a consequence, also on the number of charges in the ion binding sites of the ion pumps (21). This property allows interpretation of the standard experiment depicted in Figure 2B,C. Upon addition of a saturating $\mathrm{NaCl}$ concentration, the protons in the binding sites are replaced by $\mathrm{Na}^{+}$, and finally three $\mathrm{Na}^{+}$ions are bound which produce the observed fluorescence decrease according to the detection mechanism of RH421 (20). Release of the three $\mathrm{Na}^{+}$ions in the P-E $\mathrm{E}_{2}$ conformation induces the fluorescence increase upon addition of ATP. This maximal fluorescence change represents the effect on the 
styryl dye by the release of three elementary charges per pump. When the pumps are kept under turnover conditions, as obtained after the addition of $\mathrm{KCl}$, a fluorescence level appears which is equivalent to an average occupation of the binding sites somewhere between two and three ions. This level is induced by a mixture of occluded states $\left(\mathrm{Na}_{3}\right) \mathrm{E}_{1}-\mathrm{P}$ and $\mathrm{E}_{2}\left(\mathrm{~K}_{2}\right)$ which are both the states that precede the rate-limiting steps of the $\mathrm{Na}^{+}$and $\mathrm{K}^{+}$ translocating half-cycles of the Post-Albers scheme.

When the corresponding experiments with solubilized pumps and membrane fragments are compared as in panels B and C of Figure 2, the shape of the fluorescence traces is comparable, but the amplitudes of the relative fluorescence changes are smaller by a factor of 4 in the case of the solubilized enzyme. Since the absolute signal:noise ratio is comparable in both experiments, the substrate-induced changes are less accurately quantifiable for the solubilized Na,K-ATPase. The essential reason of this considerable difference is the presence of a significant concentration of $\mathrm{Na}, \mathrm{K}$-ATPase-free lipid/detergent micelles or micelles that contain contaminating protein represented by the bands at 60 and $75 \mathrm{kDa}$ (Figure 1A). These Na,K-ATPase-free micelles also bind RH421 and thus contribute to a higher constant fluorescence background, $F_{0}$, that is not affected by substrate additions but reduces the normalized fluorescence changes.

In summary, it can be stated that the solubilized Na,K-ATPase undergoes the same ion binding and release steps as sodium pumps in native membrane fragments.

Ion Binding Affinities in the $\mathrm{E}_{1}$ Conformation of the $\mathrm{Na}$, $K$-ATPase. In the next set of experiments, the effect of detergent solubilization on ion binding in the $\mathrm{E}_{1}$ conformation was tested. Thus, the dependence of $\mathrm{Na}^{+}$binding on $\mathrm{Na}^{+}$concentration at different $\mathrm{Mg}^{2+}$ concentrations and $\mathrm{pHs}$ was studied in equilibrium titration experiments. $\mathrm{Na}^{+}$titrations were performed in a buffer containing $9 \mu \mathrm{g}$ of Na,K-ATPase, $200 \mathrm{nM}$ RH421, $25 \mathrm{mM}$ imidazole, and $0.5 \mathrm{mM}$ EDTA at various $\mathrm{MgCl}_{2}$ concentrations and different $\mathrm{pHs}$. Small aliquots of $\mathrm{NaCl}$ were added up to $100 \mathrm{mM}$ until a maximal fluorescence decrease was obtained. Due to the small fluorescence changes in the case of the solubilized ion pumps, three to five identical experiments were performed and averaged to improve the signal:noise ratio. The result of the experiments in the presence of $5 \mathrm{mM} \mathrm{MgCl}_{2}$ and at $\mathrm{pH} 7.2$ is shown in Figure 3A. Na ${ }^{+}$binding could be fitted by the Hill function (see the legend of Figure 3 ) with a half-saturating $\mathrm{Na}^{+}$concentration $K_{1 / 2}$ of $4.9 \pm 0.3 \mathrm{mM}$ and a Hill coefficient $n$ of 2. Such titration experiments were performed in the presence of various $\mathrm{MgCl}_{2}$ concentrations between 0 and $20 \mathrm{mM}$ at $\mathrm{pH} 7.2$, and at various $\mathrm{pHs}$ between 5.5 and 8.1 , with $5 \mathrm{mM} \mathrm{MgCl}_{2}$ in the solution. A summary of the results in terms of the $K_{1 / 2}$ values is shown in Figure 3B,C. The apparent reduction of the $\mathrm{Na}^{+}$ binding affinity (or increase in $K_{1 / 2}$ ) at increasing $\mathrm{Mg}$ concentrations was reported earlier and was explained by competition between $\mathrm{Na}^{+}$and $\mathrm{Mg}^{2+}$ at a binding site on the cytoplasmic domain of the protein in the $\mathrm{E}_{1}$ conformation close to the entrance of the access channel to the transport sites in the membrane domain $(32,35)$. Occupation of the "upstream" site on the ion pathway by an $\mathrm{Mg}^{2+}$ ion is assumed to impede $\mathrm{Na}^{+}$ binding within the transport sites. The antagonism between $\mathrm{Mg}^{2+}$ and $\mathrm{Na}^{+}$for binding to the solubilized enzyme is compared with corresponding experiments performed with $\mathrm{Na}, \mathrm{K}$ ATPase in membrane fragments (Figure 3B). When the line fitting the data from the solubilized enzyme is scaled down by a factor of 0.83 , it fits the data obtained with native membrane fragments satisfactorily (dashed line). This finding indicates a
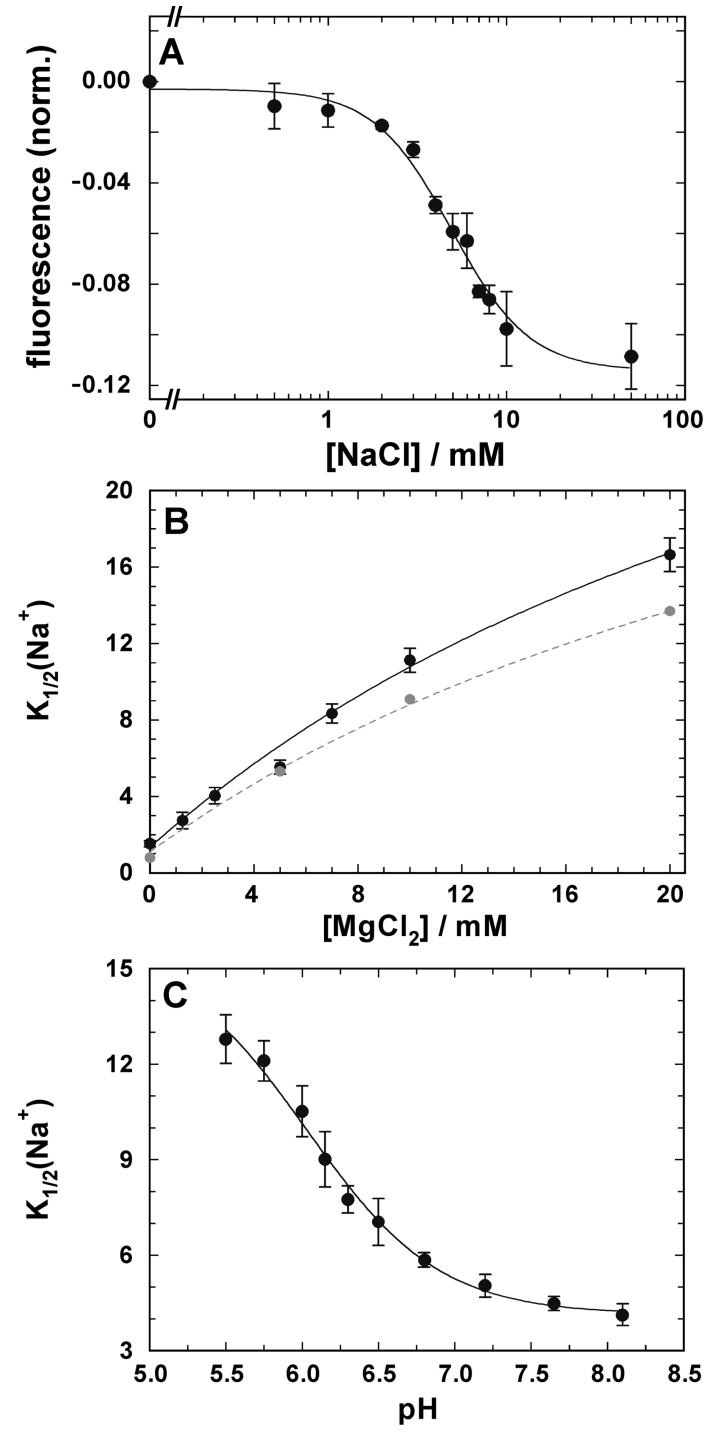

Figure 3: Equilibrium titration of the $\mathrm{Na}^{+}$binding sites in the $\mathrm{E}_{1}$ conformation of detergent solubilized Na,K ATPase. (A) The fluor escence decrease reflects the increasing occupancy of the third $\mathrm{Na}^{+}$ binding site (45). The concentration dependence can be fitted by the Hill function, $F\left(\left[\mathrm{Na}^{+}\right]\right)=\Delta F_{\max } /\left[1+\left(K_{1 / 2} /\left[\mathrm{Na}^{+}\right]\right)^{n}\right]$, with $\Delta F_{\max }$ being the maximal fluorescence decrease, $K_{1 / 2}$ the half saturating $\mathrm{Na}^{+}$concentration, and $n$ the Hill coefficient. In the presence of $5 \mathrm{mM} \mathrm{MgCl}_{2}$ at $\mathrm{pH} 7.2$, the fit (solid line) was obtained with a $K_{1 / 2}$ of $4.9 \mathrm{mM}$ and an $n$ of 2. (B) $\mathrm{Mg}^{2+}$ concentration dependence of $K_{1 / 2}$ at pH 7.2. The increasing $K_{1 / 2}$ value indicates an apparent decrease in the $\mathrm{Na}^{+}$binding affinity. The fit through the data points was determined by a binding isotherm with a $K_{1 / 2}$ of $34.7 \mathrm{mM}$. The error bars represent the standard error of the mean of the experimental data. For the sake of comparison, respective experiments for deter mining the effect of $\mathrm{Mg}^{2+}$ on $\mathrm{Na}^{+}$binding to the $\mathrm{Na}, \mathrm{K}$ ATPase in membrane fragments are included (gray points; the comparable error bars are left out for the sake of clarity). The dashed line through the data points was derived from the solid line by reducing the amplitude by $17 \%$. (C) $\mathrm{pH}$ dependence of $K_{1 / 2}$ in the presence of $5 \mathrm{mM} \mathrm{Mg}^{2+}$. The data can be fitted by a binding isotherm for $\mathrm{H}^{+}$, indicating that a direct competition occurs in the binding sites between $\mathrm{Na}^{+}$and $\mathrm{H}^{+}$.

modest systematic difference between both preparations and will be analyzed in Discussion. The competition between $\mathrm{Na}^{+}$and $\mathrm{H}^{+}$, which also leads to reduced $K_{1 / 2}$ values for $\mathrm{Na}^{+}$binding at low $\mathrm{pH}$, occurs in the transport sites since it was shown that in the $\mathrm{E}_{1}$ conformation the ion binding sites have a high affinity for protons $(34,36)$. A comparable behavior was also observed here in the case of solubilized Na,K-ATPase (Figure 3C). 


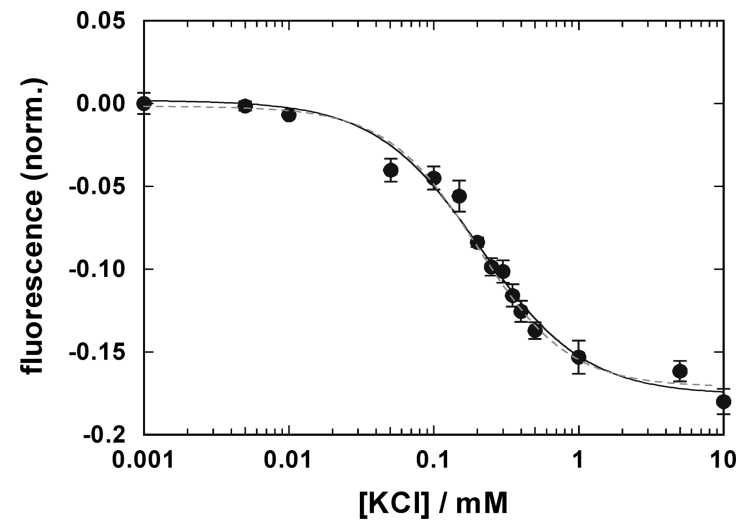

FIgURE 4: Equilibrium titration of the $\mathrm{K}^{+}$binding sites in the $\mathrm{P}_{2}$ conformation of detergent solubilized $\mathrm{Na}, \mathrm{K}$ ATPase. In the presence of $50 \mathrm{mM} \mathrm{NaCl}$ and $0.5 \mathrm{mM} \mathrm{ATP}\left(\mathrm{pH} 7.2\right.$ ), a half saturating $\mathrm{K}^{+}$ concentration of $0.2 \mathrm{mM}$ was determined by a fit of the data with the Hill function (solid line) and compared with data published pre viously for $\mathrm{Na}, \mathrm{K}$ ATPase in membrane fragments (dashed line) (37).

$K^{+}$Binding Affinities in the $P-E_{2}$ Conformation of the $\mathrm{Na}, \mathrm{K}$-ATPase. When Na,K-ATPase is equilibrated in standard buffer with $5 \mathrm{mM} \mathrm{MgCl} 2,50 \mathrm{mM} \mathrm{NaCl}$, and $500 \mu \mathrm{M} \mathrm{ATP} \mathrm{(pH}$ 7.2), the $\mathrm{P}-\mathrm{E}_{2}$ state with virtually empty binding sites is maintained since the $P-E_{2} \rightarrow E_{1}$ back reaction is so slow compared to the $\mathrm{Na}^{+}$-translocating forward reaction that it may be neglected. Thus, extracellular $\mathrm{K}^{+}$binding can be studied by $\mathrm{K}^{+}$titration experiments (37). The averaged result of such experiments is shown in Figure 4. When the fluorescence amplitude of the data from membrane fragments (37) is adjusted to that of the solubilized enzyme, the concentration dependencies of both preparations agree perfectly with a $K_{1 / 2}$ of $0.20 \pm 0.01 \mathrm{mM}$, indicating that the $\mathrm{K}^{+}$binding affinity is not affected by solubilization of the ion pump with DDM.

Backdoor Phosphorylation. The last set of experiments in which functions of solubilized and membrane-bound $\mathrm{Na}, \mathrm{K}$ ATPase were compared was the phosphorylation of the enzyme by inorganic phosphate, $\mathrm{P}_{\mathrm{i}}$, in the absence of $\mathrm{Na}^{+}$and $\mathrm{K}^{+}$ions (Figure 2A). Due to the fact that the $\mathrm{H}^{+}$binding affinity in the $\mathrm{E}_{1}$ conformation is significantly higher than in $\mathrm{P}-\mathrm{E}_{2}$, the partial reaction $\mathrm{H}_{n} \mathrm{E}_{1} \rightarrow \mathrm{E}_{2}\left(\mathrm{H}_{2}\right) \rightarrow \mathrm{P}-\mathrm{E}_{2} \mathrm{H}_{2} \rightarrow \mathrm{P}-\mathrm{E}_{2}+2 \mathrm{H}^{+}$is electrogenic because of the release of both protons, and the proton release can be detected by the RH421 method (36). With enzyme in the standard buffer, so-called backdoor phosphorylation was triggered by addition of $500 \mu \mathrm{M}$ Tris phosphate, producing a fluorescence increase due to release of two $\mathrm{H}^{+}$ions in the $\mathrm{P}-\mathrm{E}_{2}$ conformation (Figure 5). The reaction could be reversed in two different ways. First, by addition of $500 \mu \mathrm{M}$ ATP, a faster process (with a time constant of $\sim 1-2 \mathrm{~s}$ ) shifts the equilibrium state of the enzyme from P-E $\mathrm{E}_{2}$ to $\mathrm{H}_{2} \mathrm{E}_{1}$. ATP (trace a) (and then addition of $\mathrm{Na}^{+}$causes phosphorylation by ATP to state $\mathrm{P}-\mathrm{E}_{2}$ ). The second is by addition of $50 \mathrm{mM} \mathrm{NaCl}$, which induces a slower transition (with a time constant of $\sim 40$ s) to state $\mathrm{Na}_{3} \mathrm{E}_{1}$ (trace b). When the ion pumps are transferred to state $\mathrm{P}-\mathrm{E}_{2}$ by the addition of ATP and $\mathrm{NaCl}$, further addition of $\mathrm{P}_{\mathrm{i}}$ does not have any significant effect (trace c). All these findings are in perfect agreement with the corresponding experiment performed with $\mathrm{Na}, \mathrm{K}$-ATPase in membrane fragments (36).

Application to Recombinant Na,K-ATPase from P. pastoris. With the knowledge that the method is able to reproduce the kinetic data obtained from native membrane fragments with detergent-solubilized preparations, a first application was the
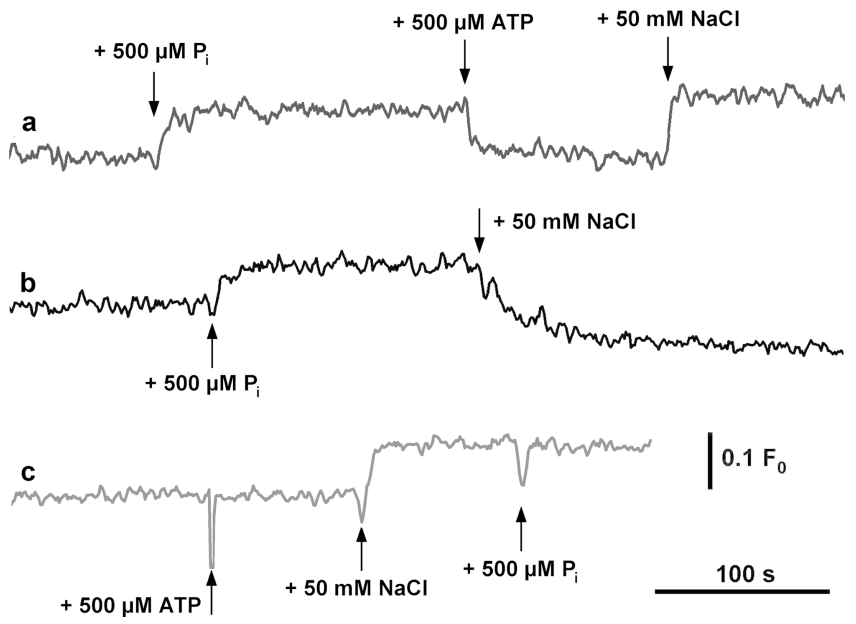

FIGURE 5: Backdoor phosphorylation of solubilized Na,K ATPase monitored by RH421. In the absence of $\mathrm{Na}^{+}$and $\mathrm{K}^{+}$, the enzyme can be phosphorylated by inorganic phosphate, $\mathrm{P}_{\mathrm{i}}$. Dephosphoryla tion can be induced either by ATP, which leads to state $\mathrm{H}_{2} \mathrm{E}_{1}$. ATP (trace a), or by $\mathrm{NaCl}$, which leads to state $\mathrm{Na}_{3} \mathrm{E}_{1}$ (trace b). Addition of $\mathrm{NaCl}$ in the presence of ATP causes the transition to state $\mathrm{P} \mathrm{E}_{2}$ (trace $\mathrm{a}$ and $\mathrm{c}$ ). Addition of $\mathrm{P}_{\mathrm{i}}$ ion to the state $\mathrm{P} \mathrm{E}_{2}$ has no significant effect (trace c).

investigation of recombinant Na,K-ATPase in DDM-solubilized form purified from $P$. pastoris. Standard experiments performed with human $\alpha 1 /$ his $-\beta 1$ and $\alpha 2 /$ his- $\beta 1$ complexes are shown in Figure 6A. The experiments performed with $\alpha 1 /$ his- $\beta 1$ show fluorescence changes upon substrate addition larger than those achieved with $\alpha 2$ /his- $\beta 1$. This observation may be explained in two different ways. Either the $\alpha 2$ preparation is less resistant to the isolation procedure and is partially inactivated, or the $\alpha 2$ preparation contains more protein-free lipid/detergent micelles. The enzyme activity of the used preparations was $846 \mu \mathrm{mol}$ of $\mathrm{P}_{\mathrm{i}}$ (mg of protein) ${ }^{1} \mathrm{~h}^{1}(\alpha 1)$ and $510 \mu \mathrm{mol}$ of $\mathrm{P}_{\mathrm{i}}(\mathrm{mg}$ of protein) ${ }^{1} \mathrm{~h}{ }^{1}(\alpha 2)$ at $37{ }^{\circ} \mathrm{C}$. This difference probably explains most of the observed discrepancy in the fluorescence response, while minor contributions may be caused by different lipid: detergent:protein ratios in both preparations. When compared with the standard experiment performed with rabbit $\mathrm{Na}, \mathrm{K}$ ATPase (Figure 2), we can see that the fluorescence changes are larger than in the case of the solubilized rabbit enzyme but are somewhat smaller than in the case of the membrane fragments. An obvious explanation is that the RH421 response is reduced in the different environment of the recombinant $\mathrm{Na}, \mathrm{K}-\mathrm{ATPase}$ formed by lipids from the yeast, SOPS, cholesterol, and $\mathrm{C}_{12} \mathrm{E}_{8}$, and the DDM micelles in which the renal Na,K-ATPase molecules are incorporated.

The $\mathrm{Na}^{+}$binding affinity was determined by $\mathrm{Na}^{+}$equilibrium titration experiments for both isoforms in the presence of various $\mathrm{MgCl}_{2}$ concentrations. Standard buffer was used at $\mathrm{pH} 7.2$ for both preparations as in the case of the rabbit enzyme preparations (Figure 3). The $\mathrm{Na}^{+}$-dependent fluorescence decrease could be fitted by a Hill curve (not shown), and the half-saturating $\mathrm{Na}^{+}$ concentration $\left(K_{1 / 2}\right)$ was determined and plotted against the $\mathrm{Mg}^{2+}$ concentration. The results are shown in Figure 6B. No significant differences could be found between the $\alpha 1 /$ his- $\beta 1$ and $\alpha 2 /$ his- $\beta 1$ enzymes, and the values are quite similar to those found for $\alpha 1 \beta 1$ from rabbit kidney. In the absence of $\mathrm{MgCl}_{2}$, the half-saturating $\mathrm{Na}^{+}$concentration was $0.40 \pm 0.02 \mathrm{mM}$, and at $5 \mathrm{mM} \mathrm{MgCl}_{2}$, it was $5.6 \pm 0.3 \mathrm{mM}$ when averaged over both enzymes. The Hill coefficient varied between $1.1 \pm 0.1$ (at low 

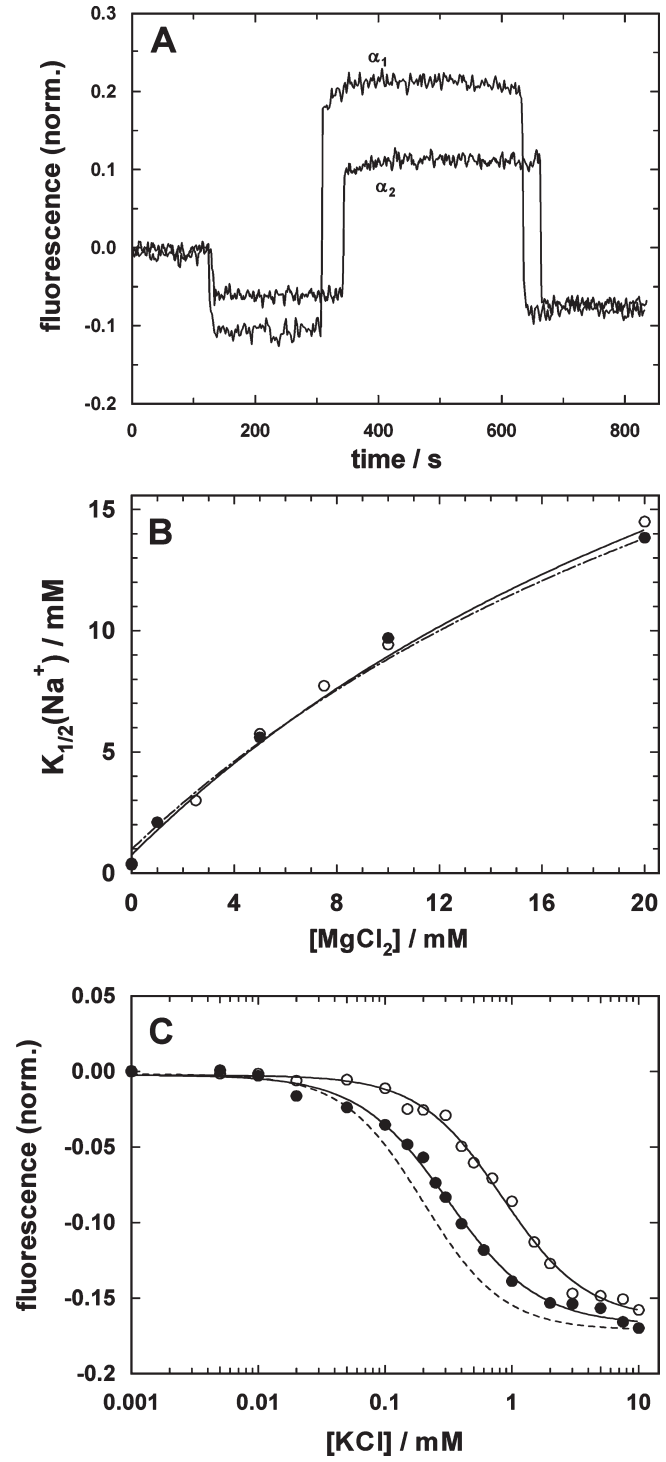

FIGURE 6: Fluorescence experiments performed with DDM solubi lized recombinant human $\alpha 1 /$ his $\beta 1$ and $\alpha 2 /$ his $\beta 1 \mathrm{Na}, \mathrm{K}$ ATPases isolated form $P$. pastoris. (A) Standard experiments, under the experimental conditions given in the legend of Figure 2. Fluorescence changes were induced by successive addition of $50 \mathrm{mM} \mathrm{NaCl}, 0.5 \mathrm{mM}$ ATP, and $20 \mathrm{mM} \mathrm{KCl}$. (B) Half saturating $\mathrm{Na}^{+}$concentrations $\left(K_{1 / 2}\right)$ obtained from equilibrium titration experiments in the $\mathrm{E}_{1}$ conformation in the presence of various $\mathrm{Mg}^{2+}$ concentrations. $\alpha 1 /$ his $\beta 1(\bullet)$ and $\alpha 2 /$ his $\beta 1(\bigcirc)$ do not differ significantly. To indicate the $\mathrm{Mg}^{2+}$ dependence, a solid line is drawn to guide the eye. When these results are compared to corresponding results from rabbit kidney Na,K ATPase in membrane fragments (dashed line), no significant differences can be seen. (C) Equilibrium titration of the $\mathrm{K}^{+}$binding sites in the $\mathrm{PE}_{2}$ conformation, under experimental conditions given in the legend of Figure 4. Half saturating $\mathrm{KCl}$ concentrations $\left(K_{1 / 2}\right)$ of $0.31 \mathrm{mM}[\alpha 1 /$ his $\beta 1(\bullet)]$ and $0.84 \mathrm{mM}[\alpha 2 /$ his $\beta 1(\bigcirc)$ ] reflect a significant difference between both isoforms. The solid lines represent fits of the Hill function to the data. The $\mathrm{K}^{+}$ binding affinity of the rabbit $\alpha 1$ enzyme is slightly higher $\left[K_{1 / 2}=\right.$ $0.2 \mathrm{mM}$ (dashed line taken from Figure 4)] than that of human $\alpha 1$.

$\mathrm{Mg}^{2+}$ concentrations) and 1.6 (at high $\mathrm{Mg}^{2+}$ concentrations) and was $1.3 \pm 0.2$ averaged over all experiments.

When $\mathrm{K}^{+}$binding in the $\mathrm{P}-\mathrm{E}_{2}$ conformation was studied, significant differences between both isoforms were found (Figure 6C). The titration experiments were performed as described in the case of rabbit Na,K-ATPase (Figure 4). The concentration dependence of the fluorescence decrease was fitted by the Hill function, and the half-saturating $\mathrm{K}^{+}$concentration was $0.31 \pm 0.08 \mathrm{mM}$ for the $\alpha 1 /$ his- $\beta 1$ isoform and $0.84 \pm$ $0.05 \mathrm{mM}$ for $\alpha 2 /$ his $-\beta 1$. The Hill coefficient was in both cases $\sim 1.2 \pm 0.2$, which is not significantly different from the value obtained for the rabbit kidney enzyme.

\section{DISCUSSION}

As mentioned in the introductory section, the ion translocation process of $\mathrm{Na}, \mathrm{K}-\mathrm{ATPase}$, utilizing the electrogenic property of ion transport, may be investigated by two completely different approaches. The first approach uses electrophysiological techniques to measure charge movements with electrodes in contact with the aqueous compartments on both sides of the membrane containing the ion pumps. To measure pump-mediated currents, the ion pump is maintained first in a steady state of the catalytic cycle and then either the membrane voltage or a substrate concentration is altered rapidly, and the subsequent relaxation reaction into a new steady state is detected by the current transients generated by the Na,K-ATPase. These pre-steadystate currents are recorded and analyzed. Various preparations are used in electrophysiological assays: cardiac cells (38), oocytes $(39,40)$, squid axons (17), and purified vesicular and flat open membrane fragments adsorbed to black lipid bilayers or to solid supported membranes $(41-43)$.

The second approach makes use of electrochromic fluorescent styryl dyes, which monitor charge movements of ions in the membrane domain of ion pumps (21). There are two important features of the styryl dye method. First, the time course of the signals bears information about the kinetics of the process. Second, the amplitude of the fluorescence signal can be characterized in terms of states of the protein with defined numbers of ions bound. Thus, the number of ions per pump molecule moved in or out of the binding sites may be accurately estimated. In addition, the presence of ion channels or carriers does not affect the experiments in any significant way. These features have been utilized in numerous studies to elucidate various partial reactions of the pump cycle (for a review, see ref 1 ).

The disadvantage of the styryl dye method until now was that it could be applied only to membrane preparations that contained P-type ATPases at a high density, such as purified microsomal preparations for the Na,K-ATPase, sarcoplasmic reticulum vesicles containing Ca-ATPase (21), or vesicles containing $\mathrm{H}$, K-ATPase, isolated from parietal cells (23). An investigation of recombinant proteins expressed in oocytes, mammalian cells, or yeast cells would be desirable, but ion pumps expressed in these cells lack the crucial requirement of a sufficiently high density compared to isolated membrane preparations from enriched native sources. Therefore, the successful assay of the recombinant $\mathrm{Na}, \mathrm{K}$-ATPase isoforms described here opens the door to study all isoforms, mutants, or any other variants of ion pumps that can be isolated in a detergent-solubilized functional form. Such protein preparations have been introduced for most of the ion pumps, which are now under scrutiny.

Ion Binding Properties of the Na,K-ATPase Are the Same in Membrane-Bound and Solubilized Forms. When the standard experiment and ion binding properties of the membrane-bound and detergent-soluble Na,K-ATPase were compared, qualitatively similar fluorescence responses were found, as documented in Figures 2-4. These observations indicate that the styryl dye mechanism and the kinetic properties of the detergentsolubilized $\mathrm{Na}, \mathrm{K}$-ATPase do not differ significantly from those in quasi-native membrane preparations. 
One obvious discrepancy between membrane-bound and detergent-soluble renal Na,K-ATPase preparations is the lower signal:noise ratio and amplitude of the fluorescence changes in the detergent-soluble preparations (Figure 2). The origin of this discrepancy is the fact that the (active) $\mathrm{Na}, \mathrm{K}$ ATPase-lipid-detergent complexes are mixed with significant amounts of protein-free micelles consisting of lipids and detergent molecules or of complexes with other proteins. These micelles are also equilibrated with the fluorescent dye RH421. However, they do not contribute to the fluorescence changes during substrate-induced electrogenic partial reactions of the sodium pumps. Therefore, they produce a significant but constant background fluorescence that leads to the observed reduction in the relative fluorescence changes by a factor of $\sim 4$, and also to an apparent reduction in the signal:noise ratio. When plotted on the same scale, the unspecific fluorescence fluctuations are comparable for both types of preparations.

An improvement could be achieved by separating the $\mathrm{Na}, \mathrm{K}$ ATPase-containing micelles by size-exclusion HPLC. In this case, the eluted micelles had to be concentrated again before being applicable in the fluorescence experiments. A few tests were performed and showed the right tendency. However, this approach was not followed up systematically, since the major purpose of the investigation is to analyze the recombinant $\mathrm{Na}$, K-ATPase. The recombinant proteins have a His tag on their $\beta$ subunit, so that the isolation and purification procedure involves affinity chromatography and results in a highly purified preparation of Na,K-ATPase-lipid-detergent complexes with a low background of inactive micelles $(26,27)$. The improvement, compared to DDM-solubilized renal Na,K-ATPase, can be seen in Figure 6A as an increased signal:noise ratio. Although the fluorescence changes are still not as large as in the case of the purified membrane-bound renal $\mathrm{Na}, \mathrm{K}$-ATPase, they are sufficient for easily performing any kind of ion binding titration experiments.

A second difference between membrane fragments and solubilized ion pumps can be seen in Figure 3B with regard to the $\mathrm{Mg}^{2+}$ concentration dependence of the $\mathrm{Na}^{+}$binding affinity which is modestly but significantly lower in the case of the solubilized $\mathrm{Na}, \mathrm{K}$-ATPase. When the $\mathrm{Mg}^{2+}$ dependence of both preparations was compared, it was found that the $K_{1 / 2}$ values for the "native" Na,K-ATPase were lower by a factor of 0.83 , at all $\mathrm{Mg}^{2+}$ concentrations. This finding leads to the assumption that the difference may be caused by a different surface charge density of both membrane surfaces. The Gouy-Chapman theory allows the calculation of cation concentrations at the charged surfaces (which here corresponds to the concentration at the entrance of the access channel to the binding sites) as a function of the surface potential that is, in turn, a function of the surface charge density. On the basis of the $\mathrm{Mg}^{2+}$ concentration-independent, constant ratio of the $K_{1 / 2}$ values of both protein preparations and assuming that the $\mathrm{Na}^{+}$binding affinity is the same in both protein preparations, the difference in the surface charge density can be estimated to be $1.7 \times 10^{3} \mathrm{C} / \mathrm{m}^{2}$ (or $\sim 1$ elementary charge/ $100 \mathrm{~nm}^{2}$ ). With a cross-sectional area of a lipid molecule on the order of $0.5 \mathrm{~nm}^{2}$, this result indicates that in the case of the solubilized enzyme, on average, there is one fewer negative charge present per 200 lipid molecules compared to the situation in the membrane fragments. Such a reduction in surface charge density may be generated easily by the presence of the uncharged DDM (or $\mathrm{C}_{12} \mathrm{E}_{8}$ ) molecules in the annulus around the solubilized $\mathrm{Na}$, $\mathrm{K}$ ATPase. Nevertheless, this susceptibility to variations in surface charge emphasizes the point that, in future studies, the lipid composition of the protein-lipid-detergent complexes will have to be controlled carefully to allow a direct comparison of ion binding affinities in different preparations of ion pumps.

By contrast to $\mathrm{Na}^{+}$binding in $\mathrm{E}_{1}, \mathrm{~K}^{+}$binding to the $\mathrm{P}-\mathrm{E}_{2}$ conformation from the extracellular side of the membrane was completely unaffected by the enzyme solubilization. This indicates that the binding kinetics is unaffected by the solubilization procedure on the one hand and, in addition, that the apparent charge density of both the outer membrane leaflet and the solubilized preparation is not significantly different.

In summary, it can be stated that the Na,K-ATPase solubilized with the detergent $n$-dodecyl $\beta$-D-maltoside is an active enzyme preparation in which the kinetic properties of ion binding and release are not significantly modified compared to those of the native ion pumps in intact membrane preparations.

Comparison of Recombinant $\alpha 1$ and $\alpha 2$ Isoforms of the Na,K-ATPase. A first application of the new method was a comparison of $\mathrm{Na}^{+}$and $\mathrm{K}^{+}$binding properties of recombinant human $\alpha 1 /$ his- $\beta 1$ and $\alpha 2 /$ his- $\beta 1$ proteins purified from $P$. pastoris. In agreement with recently published data on the enzymatic properties of the isolated $\alpha 2 /$ his- $\beta 1$ preparation (28, 29 ), a lower specific enzyme activity was found compared to the $\alpha 1 /$ his- $\beta 1$ preparation. This reduction could be caused by a lower turnover rate of the $\mathrm{Na}, \mathrm{K}$-ATPase molecules or by a reduced number of active enzyme molecules. $\alpha 2 /$ his- $\beta 1$ is known to have a lower turnover rate (44). However, the smaller fluorescence increase for $\alpha 2 /$ his- $\beta 1$ upon addition of ATP (seen in Figure 6A) suggests that there is partial inactivation of $\alpha 2 /$ his- $\beta 1$, since in the absence of $\mathrm{K}^{+}$virtually all pump molecules are trapped in the phosphorylated E2P state, independent of the actual turnover rate. The fact that size-exclusion HPLC performed with $\alpha 1 /$ his- $\beta 1$ and $\alpha 2 /$ his- $\beta 1$ complexes showed that the elution profiles were more or less identical (29) indicates that possible differences in the lipid/detergent annulus around the protein may produce, if any, only a minor modification of the fluorescence changes in the standard experiments.

The next analytic step was the investigation of ion binding. When $\mathrm{Na}^{+}$binding was studied in the $\mathrm{E}_{1}$ conformation, it turned out that both isoforms had identical half-saturating $\mathrm{Na}^{+}$concentrations in the whole range of tested $\mathrm{Mg}^{2+}$ concentrations (Figure 6B), and these values correspond to those of rabbit renal $\mathrm{Na}, \mathrm{K}-\mathrm{ATPase}(\alpha 1 \beta 1)$ in native membrane fragments, as indicated in Figure 6B. Recently, the Na,K-ATPase activity of the same $\alpha 1 \beta 1$ and $\alpha 2 \beta 1$ isoform complexes was studied (29). The $K_{1 / 2}$ of $\mathrm{Na}^{+}$for activating Na,K-ATPase activity, measured in the presence of $3 \mathrm{mM} \mathrm{Mg}^{2}$, was $\sim 16 \mathrm{mM}$ for both $\alpha 1 \beta 1$ and $\alpha 2 \beta 1$ isoforms. The value of $K_{1 / 2}$ is higher by a factor of $\sim 4$ than that observed here, a fact that can be attributed to the presence of $100 \mathrm{mM} \mathrm{K}^{+}$, which is known to be a competitor of $\mathrm{Na}^{+}$in the binding sites. Nevertheless, under this condition also, the same binding properties for $\mathrm{Na}^{+}$were found in both isoforms.

By contrast, a significant difference was observed for $\mathrm{K}^{+}$ binding from the extracellular side in the E2P conformation (Figure $6 \mathrm{C}$ ). The 2.7 -fold lower $\mathrm{K}^{+}$binding affinity of $\alpha 2 \beta 1$ compared to that of $\alpha 1 \beta 1$ was the only significant difference between both isoforms in this study, confirming a difference observed previously $(29,44)$. When $\mathrm{K}^{+}$binding to the recombinant human $\alpha 1$ isoform is compared with that of the rabbit $\alpha 1$ enzyme, a minor difference can be seen (30\% higher affinity for the rabbit enzyme). Since it may be assumed that the cation binding residues themselves are not different in both isoforms, 
the slightly different binding properties may be caused by modifications in the access channel or on the protein surface close to the entrance of the access channel. The identification of the origin is part of current investigations.

Conclusions. The adaptation of the styryl dye method to recombinant detergent-solubilized $\mathrm{Na}, \mathrm{K}$-ATPase opens the door to the study of electrogenic properties and kinetics of genetically engineered ion pumps. Ion binding affinities can be determined easily and with high precision. This method may also be applied to other purified P-type ATPases available in detergent-solubilized preparations, to other classes of ion transporters such as ion carriers and cotransporters, and even to ion channels in identifying binding sites and the number of bound ions inside the ion pathway through the membrane domain.

\section{ACKNOWLEDGMENT}

We thank Milena Roudna and Nadège Devaux for excellent technical assistance.

\section{REFERENCES}

1. Apell, H. J. (2004) How do P type ATPases transport ions? Bioelec trochemistry 63, 149156.

2. Kuhlbrandt, W. (2004) Biology, structure and mechanism of P type ATPases. Nat. Rev. Mol. Cell Biol. 5, 282295.

3. Møller, J. V., Juul, B., and le Maire, M. (1996) Structural organiza tion, ion transport, and energy transduction of $\mathrm{P}$ type ATPases. Biochim. Biophys. Acta 1286, 151.

4. Scarborough, G. A. (1999) Structure and function of the P type ATPases. Curr. Opin. Cell Biol. 11, 517522.

5. Toyoshima, C., Nakasako, M., Nomura, H., and Ogawa, H. (2000) Crystal structure of the calcium pump of sarcoplasmatic reticulum at $2.6 \AA$ A resolution. Nature 405, 647655 .

6. Toyoshima, C., and Mizutani, T. (2004) Crystal structure of the calcium pump with a bound ATP analogue. Nature 430, 529535.

7. Jensen, A. M., Sørensen, T., Olesen, C., Møller, J. V., and Nissen, P. (2006) Modulatory and catalytic modes of ATP binding by the calcium pump. EMBO J. 25, 23052314.

8. Olesen, C., Picard, M., Winther, A. M., Gyrup, C., Morth, J. P., Oxvig, C., Moller, J. V., and Nissen, P. (2007) The structural basis of calcium transport by the calcium pump. Nature 450, 10361042.

9. Morth, J. P., Pedersen, B. P., Toustrup Jensen, M. S., Sorensen, T. L., Petersen, J., Andersen, J. P., Vilsen, B., and Nissen, P. (2007) Crystal structure of the sodium potassium pump. Nature 450, 10431049.

10. Shinoda, T., Ogawa, H., Cornelius, F., and Toyoshima, C. (2009) Crystal structure of the sodium potassium pump at $2.4 \AA$ resolution. Nature 459, 446450.

11. Ogawa, H., Shinoda, T., Cornelius, F., and Toyoshima, C. (2009) Crystal structure of the sodium potassium pump $\left(\mathrm{Na}^{+}, \mathrm{K}^{+}\right.$ATPase $)$ with bound potassium and ouabain. Proc. Natl. Acad. Sci.U.S.A. 106, 1374213747.

12. Sweadner, K. J., and Donnet, C. (2001) Structural similarities of Na, $\mathrm{K}$ ATPase and SERCA, the $\mathrm{Ca}^{2+}$ ATPase of the sarcoplasmic reti culum. Biochem. J. 356, 685704.

13. Albers, R. W. (1967) Biochemical aspects of active transport. Аnпu. Rev. Biochem. 36, 727756.

14. Post, R. L., Hegyvary, C., and Kume, S. (1972) Activation by adenosine triphosphate in the phosphorylation kinetics of sodium and potassium ion transport adenosine triphosphatase. J. Biol. Chem. 247,65306540 .

15. Apell, H. J. (2003) Structure Function Relationship in P Type ATPases: A Biophysical Approach. Rev. Physiol. Biochem. Pharma col. 150, 135.

16. Gadsby, D. C., Kimura, J., and Noma, A. (1985) Voltage dependence of $\mathrm{Na} / \mathrm{K}$ pump current in isolated heart cells. Nature 315, 6365.

17. Holmgren, M., Wagg, J., Bezanilla, F., Rakowski, R. F., de Weer, P., and Gadsby, D. C. (2000) Three distinct and sequential steps in the release of sodium ions by the $\mathrm{Na}^{+} / \mathrm{K}^{+}$ATPase. Nature 403, 898901

18. Borlinghaus, R., Apell, H. J., and Lauger, P. (1987) Fast charge translocations associated with partial reactions of the Na,K pump: I. Current and voltage transients after photochemical release of ATP. J. Membr. Biol. 97, 161178.
19. Fendler, K., Grell, E., Haubs, M., and Bamberg, E. (1985) Pump currents generated by the purified $\mathrm{Na}^{+} \mathrm{K}^{+}$ATPase from kidney on black lipid membranes. EMBO J. 4, 30793085.

20. Buhler, R., Sturmer, W., Apell, H. J., and Lauger, P. (1991) Charge translocation by the Na,K pump: I. Kinetics of local field changes studied by time resolved fluorescence measurements. J. Membr. Biol. $121,141161$.

21. Pedersen, M., Roudna, M., Beutner, S., Birmes, M., Reifers, B., Martin, H. D., and Apell, H. J. (2002) Detection of charge move ments in ion pumps by a family of styryl dyes. J. Membr. Biol. 185, 221236.

22. Fibich, A., Janko, K., and Apell, H. J. (2007) Kinetics of proton binding to the SR Ca ATPase in the $\mathrm{E}_{1}$ state. Biophys. J. 93, 3092 3104.

23. Diller, A., Vagin, O., Sachs, G., and Apell, H. J. (2005) Electrogenic partial reactions of the gastric H,K ATPase. Biophys. J. 88, 3348 3359 .

24. Lauger, P. (1991) Electrogenic Ion Pumps , Sinauer Associates, Sunderland, MA.

25. Loew, L. M. (1982) Design and characterization of electrochromic membrane probes. J. Biochem. Biophys. Methods 6, 243260.

26. Strugatsky, D., Gottschalk, K. E., Goldshleger, R., Bibi, E., and Karlish, S. J. (2003) Expression of $\mathrm{Na}^{+}, \mathrm{K}^{+}$ATPase in Pichia pastoris: Analysis of wild type and D369N mutant proteins by $\mathrm{Fe}^{2+}$ catalyzed oxidative cleavage and molecular modeling. J. Biol. Chem. 278, 4606446073.

27. Cohen, E., Goldshleger, R., Shainskaya, A., Tal, D. M., Ebel, C., leMaire, M., and Karlish, S. J. (2005) Purification of $\mathrm{Na}^{+}, \mathrm{K}^{+}$ATPase expressed in Pichia pastoris reveals an essential role of phospholipid protein interactions. J. Biol. Chem. 280, 1661016618.

28. Haviv, H., Cohen, E., Lifshitz, Y., Tal, D. M., Goldshleger, R., and Karlish, S. J. (2007) Stabilization of $\mathrm{Na}^{+}, \mathrm{K}^{+}$ATPase purified from Pichia pastoris membranes by specific interactions with lipids. Bio chemistry 46, 1285512867.

29. Lifshitz, Y., Petrovich, E., Haviv, H., Goldshleger, R., Tal, D. M., Garty, H., and Karlish, S. J. (2007) Purification of the human $\alpha 2$ isoform of Na,K ATPase expressed in Pichia pastoris. Stabilization by lipids and FXYD1. Biochemistry 46, 1493714950.

30. Jørgensen, P. L. (1974) Isolation of $\left(\mathrm{Na}^{+}+\mathrm{K}^{+}\right)$ATPase. Methods Enzymol. 32, 277290.

31. Schwartz, A. K., Nagano, M., Nakao, M., Lindenmayer, G. E., and Allen, J. C. (1971) The sodium and potassium activated adenosine triphosphatase system. Methods Pharmacol. 1, 361388.

32. Schneeberger, A., and Apell, H. J. (1999) Ion selectivity of the cytoplasmic binding sites of the Na,K ATPase: I. Sodium binding is associated with a conformational rearrangement. J. Membr. Biol. 168, 221228.

33. Heyse, S., Wuddel, I., Apell, H. J., and Sturmer, W. (1994) Partial reactions of the Na,K ATPase: Determination of rate constants. J. Gen. Physiol. 104, 197240.

34. Apell, H. J., and Diller, A. (2002) Do $\mathrm{H}^{+}$ions obscure electrogenic $\mathrm{Na}^{+}$and $\mathrm{K}^{+}$binding in the $\mathrm{E}_{1}$ state of the $\mathrm{Na}, \mathrm{K}$ ATPase? FEBS Lett. 532, 198202.

35. Shainskaya, A., Schneeberger, A., Apell, H. J., and Karlish, S. J. (2000) Entrance port for $\mathrm{Na}^{+}$and $\mathrm{K}^{+}$ions on $\mathrm{Na}^{+}, \mathrm{K}^{+}$ATPase in the cytoplasmic loop between trans membrane segments M6 and M7 of the $\alpha$ subunit. Proximity of the cytoplasmic segment of the $\beta$ subunit. J. Biol. Chem. 275, 20192028.

36. Apell, H. J., Roudna, M., Corrie, J. E., and Trentham, D. R. (1996) Kinetics of the phosphorylation of Na,K ATPase by inorganic phosphate detected by a fluorescence method. Biochemistry 35, 1092210930.

37. Buhler, R, and Apell, H. J. (1995) Sequential potassium binding at the extracellular side of the Na,K pump. J. Membr. Biol. 145, 165173.

38. Nakao, M., and Gadsby, D. C. (1986) Voltage dependence of $\mathrm{Na}$ translocation by the Na/K pump. Nature 323, 628630.

39. Sagar, A., and Rakowski, R. F. (1994) Access channel model for the voltage dependence of the forward running $\mathrm{Na}^{+} / \mathrm{K}^{+}$pump. J. Gen. Physiol. 103, 869893.

40. Durr, K. L., Tavraz, N. N., Zimmermann, D., Bamberg, E., and Friedrich, T. (2008) Characterization of Na,K ATPase and H,K ATPase enzymes with glycosylation deficient $\beta$ subunit variants by voltage clamp fluorometry in Xenopus oocytes. Biochemistry 47, 42884297.

41. Sokolov, V. S., Scherbakov, A. A., Lenz, A. A., Chizmadzhev, Yu. A., and Apell, H. J. (2008) Electrogenic transport of sodium ions in cytoplasmic and extracellular ion access channels of $\mathrm{Na}^{+}, \mathrm{K}^{+}$ ATPase probed by admittance measurement technique. Biochemistry (Moscow, Russ. Fed.) 2 (Suppl. Series A), 161180. 
42. Pintschovius, J., and Fendler, K. (1999) Charge translocation by the $\mathrm{Na}^{+} / \mathrm{K}^{+}$ATPase investigated on solid supported membranes: Rapid solution exchange with a new technique. Biophys. J. 76, 814 826.

43. Tadini Buoninsegni, F., Bartolommei, G., Moncelli, M. R., and Fendler, K. (2008) Charge transfer in P type ATPases investigated on planar membranes. Arch. Biochem. Biophys. 476, 7586.
44. Crambert, G., Hasler, U., Beggah, A. T., Yu, C., Modyanov, N. N., Horisberger, J. D., Lelievre, L., and Geering, K. (2000) Transport and pharmacological properties of nine different human Na,K ATPase isozymes. J. Biol. Chem. 275, 19761986.

45. Schneeberger, A., and Apell, H. J. (2001) Ion selectivity of the cytoplasmic binding sites of the Na,K ATPase: II. Competition of various cations. J. Membr. Biol. 179, 263273. 